25. Gupta D, Lis CG. Pretreatment serum albumin as a predictor of cancer survival: a systematic review of the epidemiological literature. Nutr J. 2010;9:69.

26. Jagoe RT, Goodship TH, Gibson GJ. The influence of nutritional status on complications after operations for lung cancer. Ann Thorac Surg. 2001;71: 936-43.

27. Egberts A, Mattace-Raso FU. Increased neutrophil-lymphocyte ratio in delirium: a pilot study. Clin Interv Aging. 2017;12:1115-21.

28. Fong TG, Tulebaev SR, Inouye SK. Delirium in elderly adults: diagnosis, prevention and treatment. Nat Rev Neurol. 2009;5:210-20.

29. Chandrashekara S, Mukhtar Ahmad M, Renuka P, Anupama KR, Renuka K. Characterization of neutrophil-to-lymphocyte ratio as a measure of inflammation in rheumatoid arthritis. Int J Rheum Dis. 2017;20:1457-67.

30. Shen Y, Huang X, Zhang W. Platelet-to-lymphocyte ratio as a prognostic predictor of mortality for sepsis: interaction effect with disease severity-a retrospective study. BMJ Open. 2019;9:e022896.

31. Tei M, Ikeda M, Haraguchi N, Takemasa I, Mizushima T, Ishii H, et al. Risk factors for postoperative delirium in elderly patients with colorectal cancer. Surg Endosc. 2010;24:2135-9.

32. Coussens LM, Werb Z. Inflammation and cancer. Nature. 2002;420:860-7.

33. Mantovani A, Allavena P, Sica A, Balkwill F. Cancer-related inflammation. Nature. 2008;454:436-44.

34. Hanahan D, Weinberg RA. Hallmarks of cancer: the next generation. Cell. 2011; 144:646-74.
35. Labelle M, Hynes RO. The initial hours of metastasis: the importance of cooperative host-tumor cell interactions during hematogenous dissemination. Cancer Discov. 2012;2:1091-9.

36. Degen JL, Palumbo JS. Hemostatic factors, innate immunity and malignancy. Thromb Res. 2012;129(suppl 1):S1-5.

37. Zhang L, Conejo-Garcia JR, Katsaros D, Gimotty PA, Massobrio M, Regnani G, et al. Intratumoral T cells, recurrence, and survival in epithelial ovarian cancer. $N$ Engl J Med. 2003;348:203-13.

38. Hiraoka K, Miyamoto M, Cho Y, Suzuoki M, Oshikiri T, Nakakubo Y, et al. Concurrent infiltration by $\mathrm{CD} 8+\mathrm{T}$ cells and $\mathrm{CD} 4+\mathrm{T}$ cells is a favourable prognostic factor in non-small-cell lung carcinoma. Br J Cancer. 2006;94: 275-80.

39. Kim YR, Park S, Han S, Ahn JH, Kim S, Sinn DH, et al. Sarcopenia as a predictor of post-transplant tumor recurrence after living donor liver transplantation for hepatocellular carcinoma beyond the Milan criteria. Sci Rep. 2018;8: 7157.

40. Lee EK, Ahn HJ, Zo JI, Kim K, Jung DM, Park JH. Paravertebral block does not reduce cancer recurrence, but is related to higher overall survival in lung cancer surgery: a retrospective cohort study. Anesth Analg. 2017;125:1322-8.

Key Words: prognostic nutritional index, pneumonia, postoperative complications, recurrence, thoracic surgery

\title{
Commentary: Beyond the eyeball test
}

\section{Lorraine D. Cornwell, MD, and R. Taylor Ripley, MD}

Although experienced surgeons often count on the accuracy of the "eyeball test" to advise patients, risk stratification has become more reproducible with the increasing use of risk models. With the rise in use of competing alternative treatment options, such as stereotactic body radiation therapy, further refinements in thoracic surgical risk prognostication have become even more important.

Risk models such as the VASQIP (Veterans Affairs Surgical Quality Improvement Program) surgical risk

From the Division of General Thoracic Surgery, The Michael E. DeBakey Department of Surgery, Baylor College of Medicine, Houston, Tex.

Disclosures: Authors have nothing to disclose with regard to commercial support.

Received for publication Oct 15, 2019; revisions received Oct 15, 2019; accepted for publication Oct 16, 2019; available ahead of print Oct 31, 2019.

Address for reprints: R. Taylor Ripley, MD, Division of General Thoracic Surgery, Department of Surgery, Baylor College of Medicine, 6620 Main St, Suite 1325,

Houston, TX 77030 (E-mail: R.Taylor.Ripley@bcm.edu).

J Thorac Cardiovasc Surg 2020;160:285-6

$0022-5223 / \$ 36.00$

Copyright (C) 2019 by The American Association for Thoracic Surgery

https://doi.org/10.1016/j.jtcvs.2019.10.085

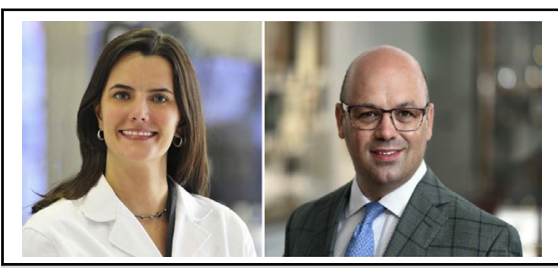

Lorraine D. Cornwell, MD (left), and R. Taylor Ripley, MD (right)

CENTRAL MESSAGE

Although surgeons use the

"eyeball test" to advise patients

about surgical risk, nutritional

indices such as the PNI may help

quantify risks beyond the VAS-

QIP, performance status, and

frailty scoring.

calculator, the Eastern Cooperative Oncology Group (ECOG) and Karnofsky performance statuses, and frailty scoring are increasingly used in multidisciplinary evaluation and in discussions with patients. Although risk models have long included nutritional factors, such as body mass index and albumin, indicators of immunologic status, such as the absolute lymphocyte 
count, C-reactive protein, and neutrophil to lymphocyte ratio have only been studied more recently. ${ }^{1}$ Enhanced recovery after surgery pathways have also increased the focus on preoperative nutritional and immune assessments and optimization.

In this issue of the Journal, Park and colleagues ${ }^{2}$ report their evaluation of the prognostic nutritional in$\operatorname{dex}(\mathrm{PNI})^{3}$ as a risk model for patients with lung cancer who underwent resection by open thoracotomy. They demonstrated that low PNI was associated with increased postoperative complications and reduced recurrence-free and overall survivals. The PNI, which is calculated with a formula that is based on preoperative albumin level and absolute lymphocyte count, is a well-established prognostic indicator that has been studied since the 1980s. The PNI reflects the nutritional, immune, and inflammation statuses of a patient. It is associated with oncologic outcomes, as well as outcomes of such other diseases as renal and heart failure. Despite the many articles throughout the medical literature showing accurate prognostication, the PNI is not popular among US surgeons. A quick search shows that the calculator is not included in either the Epocrates application or the VASQIP calculator. We found only one previous article in PubMed that evaluated PNI for outcome prediction for lung resection.

Park and colleagues ${ }^{2}$ demonstrated that a PNI lower than 50, similar to that obtained by other studies, was associated with increased risk. Because the patients in the high and low PNI groups were not completely balanced (with the low PNI group having higher aspirin use, older age, and lower hemoglobin), the groups were compared with a propensity-scoring analysis that confirmed their findings. Park and colleagues ${ }^{2}$ compared PNI with other predictive scores (neutrophil to lymphocyte ratio and C-reactive protein) and found that these other scores were not as predictive as the PNI in their population.

This work raises other questions. Do we need more scores, or is the eyeball test enough? Would we reject patients otherwise fit for surgery if the PNI was low? Perhaps those patients with a low score would be candidates for nutritional intervention, or "prehabilitation," to improve their candidacy. As enhanced recovery after surgery pathways are increasingly recommended, perhaps pathways will be established that can help mitigate the effects of the low PNI. We commend Park and colleagues ${ }^{2}$ for a study that was executed well and may improve the management of patients with lung cancer.

\section{References}

1. Chua W, Charles KA, Baracos VE, Clarke SJ. Neutrophil/lymphocyte ratio predicts chemotherapy outcomes in patients with advanced colorectal cancer. $\mathrm{Br} \mathrm{J}$ Cancer. 2011;104:1288-95.

2. Park S, Ahn HJ, Yang M, Kim JA, Kim JK, Park SJ. The prognostic nutritional index and postoperative complications after curative lung cancer resection: a retrospective cohort study. J Thorac Cardiovasc Surg. 2020;160: 276-85.e2.

3. Onodera T, Goseki N, Kosaki G. Prognostic nutritional index in gastrointestinal surgery of malnourished cancer patients. Nihon Geka Gakkai Zasshi. 1984;85: 1001-5. Japanese. 